\title{
Pengaruh Media Tanam Tanah Pasca Tambang dan Panjang Buku Terhadap Pertumbuhan Stek Tanaman Lada (Piper nigrum L.) Varietas Malonan I
}

\section{Media Influence Post Mining Land Planting and Book Length on Growth of Pepper Cuttings (Piper nigrum L.) Malonan I Varieties}

\author{
Ferdy Hidayat ${ }^{1}$, Mahdalena ${ }^{2}$, Winda Isdianti ${ }^{3}$ \\ 1 Alumni Program Studi Agroteknologi, Fakultas Pertanian, Universitas Widya Gama Mahakam Jl. KH. Wahid \\ Hasyim, Sempaja, Samarinda, Kalimantan Timur, Indonesia \\ 2 Tenaga Pendidik Program Studi Agroteknologi, Fakultas Pertanian, Universitas Widya Gama Mahakam Jl. \\ KH. Wahid Hasyim, Sempaja, Samarinda, Kalimantan Timur, Indonesia
}

2 Tenaga Kependidikan Program Studi Agroteknologi, Fakultas Pertanian, Universitas Widya Gama Mahakam Jl. KH. Wahid Hasyim, Sempaja, Samarinda, Kalimantan Timur, Indonesia

Diterima : 4 September 2019 Disetujui : 31 Desember 2019

Email : dyatferdy@gmail.com,mahda.amin@yahoo.com,windaisdianti@yahoo.com

\begin{abstract}
The Effect of Post-Mining Soil Planting Media and Book Lengths on the Growth of Pepper Cutters (Piper nigrum L.) Varieties of Malonan I, Under the guidance of Mahdalena and Iin Arsensi. The purpose of this study was to determine the response of the growth of pepper cuttings (Piper nigrum L.) Malonan I variety using postmining soil planting media. This research was carried out in Sungai Mariam Village, Anggana Subdistrict for 6 weeks from September to November 2018. The research was arranged in a Randomized Block Design (RBD) with Factorial experiments consisting of 2 factors with 3 replications. The first factor is the length of the book consists of two levels, namely s1 (length 3 books) and s2 (length 5 books). The second factor of the growing media consists of 3 levels, namely t1 (mining land), $t 2$ (mining land and manure), and t3 (mining land and compost). The results showed that the treatment of post-mining soil planting media and the length of cuttings did not have a significant effect on all parameters, when growing shoots, number of shoots, and shoot length were 2 , 4, 6 weeks after planting.
\end{abstract}

Keywords: Media Influence, Book Length, Malonan I Varieties Pepper.

\section{PENDAHULUAN}

Indonesia masuk ke dalam jajaran negaranegara penghasil lada besar dunia. produksi lada Indonesia bersaing dengan produksi lada asal Vietnam, Brazil, dan India. Produksi lada Indonesia mampu meraup pangsa pasar dunia sebanyak $17 \%$ pada tahun 2010. Walaupun begitu, eksportir lada Indonesia masih harus rutin memantau harga komoditas lada dunia berfluktuasi mengikuti perkembangan perekonomian global dan tren perdagangan komoditas perkebunan. Tidak selamanya ekspor komoditas lada rutin mengirim barang ke negara tujuan. Terkadang, komoditas lada urung di ekspor oleh eksportir karena harga komoditas lain lebih menguntungkan. Kondisi perekonomian global yang sedang lesu di negara-negara pengimpor lada juga menjadi penyebab permintaan komoditas lada menurun.

Lada di Indonesia sebagian besar diusahakan oleh rakyat. Hanya sebagian kecil yng diusahakan oleh negara dan perusahaan swasta besar. Luas lahan perkebuunan lada pada tahun 2012 sebesar
178.622 hektar. Naik sebanyak $0,64 \%$ dari tahun sebelumnya (2011) yang luasnya hanya 177.490 hektar. Jumlah total produksi lada pada tahun 2012 sebesar 88.160 ton. Produksi lada naik sebesar 1,23\% dibandingkan di tahun lalu (2011) yang hanya berproduksi sebesar 87.089 ton. Sedangkan produktivitas nasional lada berada di angka $789 \mathrm{~kg} / \mathrm{ha}$ pada tahun 2012. Produktivitas lada nasional naik tipis $(0,13 \%)$ di bandingkan dengan tahun sebelumnya yang hanya $784 \mathrm{~kg} / \mathrm{ha}$.

Wilayah-wilayah penghasil lada terbesar di Indonesia antara lain : Provinsi Lampung, Bangka Belitung, Kalimantan Timur dan Kalimantan Barat. Di Bangka Belitung, Produktivitas ladanya dapat mencapai angka $1.806 \mathrm{~kg} / \mathrm{ha} /$ tahun. Di Kalimantan Timur, produktivitas ladanya dapat mencapai angka $1.363 \mathrm{~kg} / \mathrm{ha} /$ tahun. Dari data tersebut dapat di simpulkan bahwa ada kesesuaian lahan, iklim, teknis budidaya yang benar, dan pengguanaan varietas unggul yang tepat (Yusnu, 2014).

Saat ini penelitian dengan perbanyakan menggunakan stek sudah banyak di lakukan pada berbagai macam media, tapi penggunaan media tanah yang berasal dari tanah pasca tambang 
masih jarang di lakukan. Penelitian ini di lakukan untuk mengetahui bagaimana pengaruh dari pertumbuhan stek lada dengan menggunakan media tanah pasca tambang tersebut.

\section{BAHAN DAN METODE}

Bahan yang digunakan adalah tanah pasca tambang batubara, polibag, bibit stek lada, pupuk kandang kambing, pupuk kompos, Rootone F, air, fungisida ekstrak bawang putih. Penelitian dilaksanakan selama 6 minggu terhitung bulan September 2018 - November 2018. Penelitian dilaksanakan di jalan Mahakam Desa Sungai Mariam Kecamatan Anggana Kabupaten Kutai Kartanegara Kalimantan Timur. Penelitian ini menggunakan Rancangan Acak Kelompok (RAK) Faktorial dengan 2 faktor dan di ulang

\section{HASIL DAN PEMBAHASAN}

Pembibitan merupakan tahapan dalam budidaya tanaman lada, meskipun tanaman lada sendiri dapat di tanam langsung tanpa melalui proses pembibitan. Hasil sidik ragam menunjukan bahwa faktor panjang tunas dan media tanam tidak berpengaruh nyata terhadap rata-rata saat tumbuh tunas, rata-rata jumlah tunas, dan panjang tunas umur 2, 4, dan 6 minggu setelah tanam terdapat pada tabel 1 . Hal ini di duga stek tanaman lada masih belum dapat menyesuaikan dengan keadaan lingkungan.pemberian pupuk kandang dan kompos belum menunjukan hasil yang maksimal untuk meningkatkan pertumbuhan vegetatif tanaman. sebanyak 3 kali. Faktor pertama ialah panjang stek (S) yang terdiri dari 2 taraf yaitu : s1 = panjang stek 3 buku dan s2 = panjang stek 5 buku. Faktor kedua ialah media tanam dan jenis pupuk (T) terdiri dari 3 taraf yaitu : $\mathrm{t} 1=\operatorname{tanah}$ tambang, $\mathrm{t} 2=$ tanah tambang + pupuk kandang dengan perbandingan $1: 1$ dan $\mathrm{t} 3=$ tanah tambang + pupuk kompos dengan perbandingan 1:1. Pelaksanaan penelitian ini meliputi : persiapan media tanam, pemilihan stek lada, penyiapan Rootone f, penanaman dan pengambilan data. Data hasil pengamatan dianalisis dengan menggunakan sidik ragam. Apabila terdapat pengaruh pada sidik ragam maka di lakukan uji BNT pada taraf 5\% untuk membandingkan dua rata-rata perlakuan.

Hasil uji laboratorium tanah pasca tambang batubara umur 6 tahun memiliki pH 4,54, $\mathrm{N}$ total $0,12 \%, \mathrm{P} 4,62 \%$, dan K 10\%. Dari hasil yang di dapat menunjukan bahwa kandungan tanah pasca tambang memiliki unsur hara yang sangat kecil, hal ini menyebabkan tidak berpengaruh terhadap perumbuhan stek tanaman lada tersebut. Menurut Harjadi (2013) tanaman perlu beradaptasi dalam menyerap unsur hara setelah di pindahkan dari tanah yang berbeda. Menurut Jumin (2002), apabila jumlah unsur hara makro dan mikro yang tersedia sedikit, maka hara yang di serap tanaman akan kurang hal ini berakibat pada proses fotosintesis yang sedikit dalam menghasilkan nutrisi dan berdampak pada rendahnya pertumbuhan vegetatif.

Tabel 1. Pengaruh Media Tanam dan Panjang Buku Terhadap Pertumbuhan Stek Tanaman Lada (Piper nigrum L.) Varietas Malonan

\begin{tabular}{cccccc}
\hline Perlakuan & $\begin{array}{c}\text { Muncul } \\
\text { Tunas }\end{array}$ & $\begin{array}{c}\text { Jumlah } \\
\text { Tunas }\end{array}$ & 2 Minggu & $\begin{array}{c}\text { Panjang Tunas } \\
\text { 4 Minggu }\end{array}$ & 6 Minggu \\
\hline Panjang stek (S) & tn & tn & tn & tn & tn \\
s1 & 4,44 & 0,89 & 0,09 & 0,31 & 0,58 \\
s2 & 5,89 & 1,78 & 0,18 & 0,54 & 0,93 \\
\hline Tanah Tambang (T) & tn & tn & tn & tn & tn \\
\hline t1 & 3,44 & 1,11 & 0,12 & 0,33 & 0,54 \\
t2 & 3,17 & 0,78 & 0,10 & 0,24 & 0,47 \\
t3 & 3,72 & 0,78 & 0,05 & 0,28 & 0,49 \\
\hline Interaksi (SxT) & tn & tn & tn & tn & tn \\
\hline s1t1 & 10,00 & 1,00 & 0,10 & 0,25 & 0,52 \\
s1t2 & 7,33 & 1,00 & 0,25 & 0,57 & 1,22 \\
s1t3 & 9,33 & 0,67 & 0,07 & 0,77 & 1,17 \\
s2t1 & 10,67 & 2,33 & 0,29 & 0,97 & 1,42 \\
s2t2 & 11,67 & 1,33 & 0,20 & 0,55 & 0,95 \\
s2t3 & 13,00 & 1,67 & 0,15 & 0,57 & 1,15 \\
\hline
\end{tabular}




\section{Persentase Stek Bertunas}

Hasil penelitian menunjukan bahwa faktor perlakuan media tanam dan panjang stek menghasilkan persentase bertunas yang tinggi yaitu $83 \%$. Perlakuan stek 3 buku dan 5 buku keduanya sama memiliki potensi untuk membentuk sistem pertunasan yaitu dengan adanya primordia tunas pada stek di samping keberadaan daun. Menurut Gardner dkk (1991), jumlah dan ukuran daun di pengaruhi oleh genotip, letak daun, penuaan daun, dan jumlah ruas. pertumbuhan batang di pengaruhi oleh hormon dan cahaya, sedangkan percabangan tanaman di pengaruhi genotipe, hormon, cahaya, dan kerapatan tanaman, fotoperiod dan temperature, pemangkasan dan perumputan.

\section{Saat Tumbuh Tunas}

Salah satu alasan penggunaan stek dalam memperbanyak tanaman secara vegetatif adalah karena waktu yang diperlukan lebih cepat. Saat tumbuh tunas merupakan indikator pertumbuhan tanaman, semakin cepat saat tumbuh tunas maka dapat dikatakan bahwa semakin cepat pula waktu yang diperlukan tanaman tersebut untuk tumbuh dan berkembang. Tunas terbentuk dari sel meristem yang membelah dan membentuk jenggul/pembengkakan pada ujung batang. Jenggul/pembengkakan itu meluas dan melingkari daerah ujung (Gardner dkk, 1991).

Berdasarkan hasil analisis data menunjukan bahwa faktor media tanam dan panjang stek tidak berpengaruh nyata pada saat tumbuh tunas. Hal ini ada hubungannya dengan pupuk yang di berikan yang belum dapat di manfaatkan secara maksimal oleh stek tanaman lada.

Rata-rata pada saat tumbuh tunas tercepat adalah pada perlakuan s1t2 yaitu 7 hst sedangkan yang terendah s2t3 yaitu 13 hst. Salisbury dan Ross (1995) menyatakan bahwa pertumbuhan pada tanaman berlangsung terbatas pada beberapa bagian tertentu,yang terdiri dari sejumlah sel yang baru saja di hasilkan melalui proses pembelahan sel meristem.produk pembelahan sel itulah yang tumbuh dan menyebabkan pertumbuhan. Ujung tajuk mempunyai meristem yang dapat membentuk tunas. Jadi saat tumbuh tunas di prngaruhi oleh meristem.

Edmond dkk (1983) menyatakan bahwa ketersediaan karbohidrat dan nitrogen juga sangat menentukan dalam proses pertumbuhan akar dan tunas pada stek. Kehadiran tunas sangat penting terhadap proses inisiasi akar, karena akar juga sebagai tempat penghasil auksin yang akan di translokasikan ke dasar potongan stek dan di perlukan untuk diferensiasi sel.

Harjadi (1983) menyatakan bahwa pembelahan sel yang terjadi pada titik tumbuh batang dan ujung-ujung akar tergantung pada ketersediaan karbohidrat yang cukup tinggi, tetapi Rismunandar (1988) menambahkan bahwa bila karbohidrat suatu stek rendah maka proteinnya tinggi, stek yang demikian akan lebih pesat pertumbuhan tunasnya dari pada akarnya.

\section{Jumlah Tunas}

Tanaman lada memiliki nodia (buku) sebagai tempat keluar akar ataupun tunas dan internodia (ruas) yang memisahkan antara nodia satu dengan nodia yang lain. Macam media, konsentrasi auksin dan kombinasi keduanya berpengaruh tidak nyata terhadap jumlah tunas. Hal ini karena jumlah tunas yang merupakan bagian dari pertumbuhan tanaman lebih dipengaruhi oleh meristem yang ada pada bahan stek yang digunakan. Sel meristem tersebut akan membelah menghasilkan sel baru, kemudian sel baru akan tumbuh dan berkembang yang menyebabkan pertumbuhan (Salisbury dan Ross, 1995). Berdasarkan hasil analisis data menunjukan bahwa faktor media tanam dan panjang stek tidak berpengaruh nyata terhadap Jumlah Tunas. Hal ini di duga unsur hara yang tersedia belum dapat dimanfaatkan secara maksimal oleh stek tanaman lada sehingga mempengaruhi pertambahan jumlah tunas. Ratarata Jumlah tunas terbanyak adalah pada perlakuan s2t2 yaitu 2,33 dan yang terendah pada perlakuan s1t3 yaitu 0,67.

Sutedjo (2008), pertumbuhan tidak akan berpengaruh terhadap perkembangan daun, batang, dan akar apabila pupuk yang di berikan belum di serap seluruhnya oleh tanaman. Hal ini menunjukan bahwa yang terdapat dalam tubuh tanaman sangat berhubungan dengan pertumbuhannya.

\section{Panjang Tunas}

Pertumbuhan tinggi batang terjadi di dalam meristem interkalar dari ruas. Ruas itu memanjang sebagai akibat meningkatnya jumlah sel dan terutama karena meluasnya sel. Pertumbuhan karena pembelahan sel terjadi pada dasar ruas. Bukan meristem ujung. Jumlah hormon pada meristem interkalar terbatas karena hormon ini tidak di produksi sendiri seperti yang terjadi pada meristem ujung maka pengatur pertumbuhannya harus di pasok dari luar (Gardner dkk, 1991). 
Hasil analisis data menunjukan bahwa faktor media tanam dan panjang stek tidak berpengaruh nyata terhadap panjang tunas umur 2,4 , dan 6 Minggu setelah tanam. Hal ini di duga media tanam mempengaruhi pertumbuhan paniang tunas yang tidak maksmial dalam peny 64 unsur hara. Rata-rata panjang tunas pada minggu ke 6 pada perlakuan s2t1 yaitu $3 \mathrm{~cm}$ sedangkan yang terendah pada perlakuan s1t1, s1t3, dan $\mathrm{s} 2 \mathrm{t} 2$ yaitu $1 \mathrm{~cm}$.

Potensi tanah sebagai media tanam di tentukan oleh faktor seperti tekstur dan struktur. Struktur tanah akan mempengaruhi sirkulasi udara di dalam tanah, laju infiltrasi, gerakan air, penetrasi akar, pencucian hara dan perkembangan akar (Osman 1996).

\section{DAFTAR PUSTAKA}

Ardana, R.C. 2009. Pengaruh Macam Zat Pengatur Tumbuh dan Frekuensi Penyemprotan terhadap Pertumbuhan Awal Bibit Gelombang Cinta.

Artanti, F.Y. 2007. Pengaruh Macam Pupuk Organik Cair dan Konsentrasi IAA Terhadap Pertumbuhan Setek Tanaman Stevia (Stevia rebaudiana Bertoni M.). Skripsi S1 FP UNS Surakarta.

Diratpahgar. 2008. Budidaya lada yang baik dan sehat.http://ditjebun.deptan.go.id/ akses September 2018.

Gardner, F.P., R.B.Pearce; dan R.L.Mitchell. 1991. Fisiologi Tanaman Budidaya. Terjemahan H. Susilo UI. Press Jakarta.

Harjadi, S.S. 2003. Pengantar Agronomi. Wiramedia Pustaka Utama, Jakarta.

Jumin, H.B. 2002. Rancangan Percobaan : Teori dan Aplikasi. Raja Grafindo Persada, Jakarta.

Marsono dan Paulus Sigit. 2005. pupuk akar jenis dan aplikasi. Penebar Swadaya, Jakarta.

Mansur I. 2008. Pemilihan Jenis Tanaman Kehutanan Untuk Rehabilitasi Lahan Bekas tambang. Bandung

Novizan. 2005. Petunjuk Pemupukan yang Efektif. AgroMedia Pustaka. Jakarta.
Lakitan (1995) menambahkan bahwa media yang ideal adalah media yang bisa menyediakan hara mineral, air dan memiliki aerasi yang baik sehingga kebutuhan oksigen terpenuhi.

\section{KESIMPULAN}

1. Media tanam tidak berpengaruh nyata terhadap rata-rata saat tumbuh tunas, jumlah tunas, dan panjang tunas umur 2, 4, dan 6 minggu setelah tanam.

2. Panjang stek tidak berpengaruh nyata terhadap rata-rata saat tumbuh tunas, jumlah tunas, dan panjang tunas umur 2, 4, dan 6 minggu setelah tanam.

3. Interaksi antara kedua faktor media tanam dan panjang stek tidak berpengaruh nyata terhadap semua parameter.

Nurdiansyah, A. 2007. Pengaruh Macam Media dan Konsentrasi IAA Terhadap Pertumbuhan Tunas dari Stek Daun Tanaman Lidah Mertua (SansevieriaThunb). Skripsi SI FP UNS Surakarta.

Rineksane, I.A. 2005. Pengaruh Lama Perendaman Biji dalam Auksin Terhadap Perkecambahan dan Pertumbuhan Akar Manggis. Jurnal Ilmu-ilmu Pertanian Agr UMY. Vol.13(2):83-91.

Rismunandar. 1984. Lika-liku Bertanam Anggur. Penerbit Sinar baru, Bandung

Rudianto, B.; R.Widarawati; dan Purwanto. 2008. Pengaruh Penambahan BahanOrganik dan Pemupukan ZA terhadap Pertumbuhan dan Hasil Tanaman Bawang Merah di Lahan Pasir Pantai.AgrosainsVol.10(1):6-14.

R.G. Halfacre, 1983. Fundamental of horticulture. 4 th Ed., Mc Graw. Hill publ., co., Ltd., NewDelhi

Setiadi Y. 2009. Revegetasi Lahan Pasca Tambang. Bogor

Setiyono, R.T.; D.Manohara; S.Wahyuni; dan Nursalam. 2004. Lada Hibrida Harapan Tahan Terhadap Penyakit BPB. Prosiding Simposium IV Hasil Penelitian Tanaman Perkebunan Bogor 28-30 September 2004.

Sastrosupadi, A. 2000. Rancangan Percobaan Praktis Bidang Pertanian. Kanisius, Yogyakarta. 
Sutedjo, M.M 2008. Pupuk dan Cara Pemupukan. Penerbit Bhineka Cipta, Jakarta.

Wasito, A. dan W.Nuryani. 2005. Dayaguna Kompos Limbah Pertanian Berbahan Aktif Cendawan Gliocladium terhadap Dua Varietad Krisan. J.Hort.
Sulibury, F.B dan C.W. Ross, 1995. Fisiologi Tumbuhan Jilid I. ITB Bandung.

Yusnu I.N. 2014. Perkebunan Lada Cepat Panen. Penerbit Infra Pustaka, Jakarta. 